\title{
From channel management towards network coordination - changing perspectives on distribution arrangements
}

\author{
Lars-Erik Gadde \\ Department of Technology Management and Economics, Chalmers University of Technology, Gothenburg, Sweden
}

\begin{abstract}
Purpose - The purpose of this paper is to examine the transformation of the perspective applied to distribution structures in the late 1900s. This change implied that the previous focus on channel management by a channel captain was abandoned because of changes in the business reality. This perspective was replaced by models and concepts featuring collaboration and joint coordination between actors and relationships embedded in networks.

Design/methodology/approach - Changes of perspectives on phenomena are assumed to occur through the dynamic interplay between business reality, the conceptualisation of this reality and the managerial recommendations derived from this conceptualisation. The study is based on a thorough longitudinal literature review.

Findings - Shifts of perspectives occur when there is an increasing mismatch between the current business reality and mainstream conceptualisations. In this transformation, new constructs are required to illustrate new aspects of the business reality, exemplified in the study by interaction and networks. Some established concepts lose their significance, illustrated by the channel captain. Others may be re-interpreted, as is the case with the power concept. The study also shows that "forgotten" conceptualisations can be re-wakened, exemplified by the view of distribution structures as network constellations. In turn, these changes in the conceptualisation of distribution impact the managerial recommendations.

Originality/value - To the best of the author's knowledge, there are no previous studies analysing how the perspective on a certain phenomenon changes through the dynamic interplay between business reality, conceptualisations and managerial recommendations.
\end{abstract}

Keywords Marketing channels, Distribution dynamics, Distribution networks, Joint coordination, Perspective shifts

Paper type Research paper

\section{Introduction}

For several decades, the perspective on channels of distribution (marketing channels) was dominated by the "channel management" approach (Gripsrud, 2004). The central features of channel management are portrayed in, for example, Stern and ElAnsary (1982) and Rosenbloom (1987). According to this perspective, a "channel captain", typically the manufacturer, was assumed to be responsible for managing the entire constellation of firms involved in the distribution arrangements. The managerial actions recommended were based on the exploitation of various power sources, which in many situations caused tensions and conflicts amongst the parties involved. These features triggered a short-term view of the business exchange between the manufacturer and its counterparts that most often were kept at an arms-length distance (Hoyt and Huq, 2000). These conditions made business partners easily replaceable, as business exchange primarily concerned standardised items.

Over time, however, changing conditions eroded the base for the channel management approach. Firstly, the channel concept was increasingly questioned by representatives of various schools of

The current issue and full text archive of this journal is available on Emerald Insight at: https://www.emerald.com/insight/0885-8624.htm

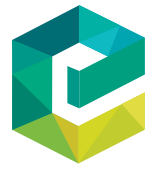

Journal of Business \& Industrial Marketing 36/13 (2021) 42-53

Emerald Publishing Limited [ISSN 0885-8624] [DOI 10.1108/JBIM-05-2020-0244] thought (Narus and Anderson, 1996; Gadde and Ford, 2008; Krafft et al., 2015). The common denominator of these advocates was that distribution arrangements over time have evolved towards network-like constellations, thus making the channel view less appropriate. Secondly, in these constellations, the managerial actions applied in channels, founded in the marketing management approach, were no longer considered adequate. Rather than being orchestrated by a channel captain, network constellations rely on joint coordination amongst more equal business partners (Gadde, 2004; Payan, 2007; Brown and Crosno, 2019). Consequently, the previous perspective on distribution based on channel management was over time replaced by an alternative one, taking the starting point in network coordination.

The aim of this paper is to illustrate this transformation from channel management towards network coordination: to analyse the underlying reasons for the shift and its associated consequences. The study builds entirely on a broad literature

(C) Lars-Erik Gadde. Published by Emerald Publishing Limited. This article is published under the Creative Commons Attribution (CC BY 4.0) licence. Anyone may reproduce, distribute, translate and create derivative works of this article (for both commercial and non-commercial purposes), subject to full attribution to the original publication and authors. The full terms of this licence may be seen at http://creativecommons.org/licences/ by/4.0/legalcode

Received 19 May 2020

Revised 10 September 2020

22 November 2020

Accepted 10 January 2021 
survey. The transformation discussed in this paper has no clear starting point. Nor is it possible to conclude when the new perspective had replaced the previous one. Transformations evolve over time through changes in various dimensions, implying that the literature survey must be broad and span a long time period. Because of the transformation's process characteristics, findings in one literature source may relate back to papers that passed unnoticed when they were published, as it was not evident at the time that they represented aspects of a successively evolving perspective.

\section{Research framing}

The analysis of the transformation of the perspective on distribution requires framing of the meaning of "perspective" that has been used in quite an abstract way so far. The perspective on a business phenomenon such as a channel of distribution (or e.g. pricing or procurement), is in this study considered to be patterned by three aspects. The first one is the theoretical roots the concepts and models that are applied in the framing of the phenomenon. This aspect is identified as the "conceptualisations of the business reality". The second relates to the practical side and the managerial consequences of the conceptualisations here labelled "managerial recommendations". The third aspect is derived from the business context where the phenomenon resides, denoted as "features of the business reality" (Figure 1).

One and the same phenomenon can be viewed from various perspectives depending on the features of the three aspects and their interplay. In this paper, we deal with two perspectives on channels of distribution. Examples of perspectives in other contexts include value-based pricing and cost-based pricing, originating in different views of the pricing phenomenon. In procurement, single-sourcing and multiple sourcing are derived from differing perceptions of purchasing efficiency. On this basis, two perspectives of a phenomenon can be evaluated through comparison and analysis regarding the three aspects in Figure 1.

This paper takes a further step in the investigation of the features of perspectives. The focus of the paper is on the dynamics of the perspective on a phenomenon - the transformation from channel management to network coordination. The perspective on a phenomenon is never stable. All the time it is affected by ongoing changes in the business reality, the refining of concepts and models and the modifications of managerial recommendations. Through the interplay amongst the three aspects, the perspective is continually evolving. These conditions cause some problems for the analysis of the transformation from one perspective to another one. There is no distinct point in time when it can be argued that channel management was replaced as the main

Figure 1 Three aspects of the perspective on a phenomenon

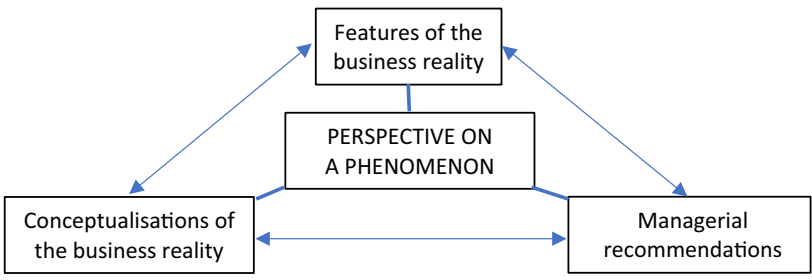

approach to distribution. Based on previous studies it seems that channel management was the dominant perspective from the middle of the 1970s to the millennium shift (Wilkinson, 2001; Wilkie and Moore, 2003). However, as is shown in this paper, network conceptualisations had been advocated even before the launch of channel management. In a similar vein, the channel management perspective, to some extent, continues to be applied for both conceptualisations and managerial recommendations.

The three aspects in Figure 1 have been significant in the transformation from channel management towards network coordination as illustrated by the following example. Firstly, the features of the business reality were affected by technological developments in production, logistics and information exchange. These improvements enabled, for example, suppliers to respond to buying firms' demands for flexible and customised solutions as a complement to standardised items (Kozlenkova et al., 2015). Secondly, the new arrangements featured increasing interdependences and required enhanced cooperation with business partners. For this reason, previous conceptualisations relying on atomistic actors on arm's-length distance and coercive power were now complemented with models portraying collaborative relationships (Swoboda et al., 2008; Ellram and UeltschyMurfield, 2019). Thirdly, on this basis, the managerial attention shifted from the exploitation of power in short-term exchange episodes towards joint actions in long-term business relationships (Wilkinson, 2001; Gadde and Ford, 2008). Altogether, these dynamics "challenged the principle of channel management and eventually lead to its fall" (Gadde, 2016, p. 146). In the example, the transformation is described as originating in changes of the business reality, in turn, impacting on conceptualisations and managerial recommendations. However, the changes may also take other directions in this interplay. For example, the managerial recommendations may impact the business reality, which, in turn, calls for new conceptualisations and vice versa.

\section{The literature study}

As mentioned in the introduction, the paper is based on a survey of literature dealing with the development of distribution arrangements, with a special focus on the features of channel management and the evolution of the alternative perspective identified as network coordination. The study is part of a longitudinal research project on the long-term dynamics of distribution, involving a comprehensive literature review. The references used in this paper represent a minor share of what was captured in the total review. Other references have been used in some previous publications related to the long-term project but have also indirectly impacted the content of this paper.

The dynamics over time of the business reality in distribution was analysed in Gadde (2014) with specific attention to the consequences for intermediaries. The evolution of theory was discussed in Gadde and Hulthén (2016) where the authors analysed similarities and differences between the frameworks of Alderson $(1957,1965)$ and those based on theories developed within IMP (Håkansson and Snehota, 1995). Central aspects of the channel management epoch were explored in Gadde (2016), with special emphasis on its roots, the main features 
and the managerial recommendations. The references selected for this paper are those in previous publications that showed to be most relevant for the analysis of the central issues in this study: the evolution of the business reality, the conceptualisations of this reality and the managerial recommendations.

This longitudinal literature analysis generated some interesting observations regarding the evolution of the publications in the research field. Based on the entire review it is obvious that the pioneering writers at the beginning of the 1900s relied on books, simply because marketing journals were not established until the late 1920s. Over time, scientific journals became increasingly significant. Around 1960 it seems as journals had become more important than books as outlets for research, although Alderson's central contributions were presented in books. During the channel management era, three journals were totally dominant when it comes to research on distribution: Fournal of Marketing, Fournal of Marketing Research and fournal of Retailing. The transformation period features quite another publication pattern where a huge number of journals in various fields publish papers on distribution. JM, JMR and JR are still important outlets for distribution research but are now supplemented with journals related to, for example, logistics, supply chain management and operations management. The enhanced attention to, and from, journals in these fields, is probably an outcome of the increasingly holistic perspective required for an understanding of the phenomenon. Furthermore, distribution researchers, over time, increasingly publish in journals dedicated to business marketing such as Industrial Marketing Management and Fournal of Business and Industrial Marketing.

The analysis of the transformation from channel management to network coordination is based on the changes related to the three aspects in Figure 1 and the interplay amongst them. This exploration must take previous evolutions of the perspective on distribution into consideration, as history matters. Therefore, the paper begins with a short summary of previous perspectives and the main features of channel management. This is followed by analysis and discussion of the evolution of the business reality, the conceptualisations of this reality and the managerial recommendations building on these conceptualisations. The paper continues with the presentation of the two central attributes of the evolving perspective: network conceptualisations of the business reality and joint coordination in networks. The paper concludes with the most significant findings.

\section{Previous changes of the perspective on distribution}

The early literature

Channels of distribution is a well-established discipline for more than 100 years. The early literature applied a broad perspective, covering activities from raw-materials extraction to final consumption (Gripsrud, 2004). Shaw and Jones (2005) identified three main schools-of-thought in the distribution at the beginning of the 1900s. Firstly, the functional school, represented by, for example, Shaw (1912) focussed on principles for the efficient undertaking of the activities required to fulfil the distribution tasks. Secondly, the institutional school, originating in the work by Weld (1916), was concerned with the performance related to various forms of division of labour between the organisations involved. Thirdly, the commodity school analysed in which ways the features of the distributed goods impacted the arrangements, for example, through publications by Cherington (1920) and Copeland (1924). All three schools were concerned mainly with descriptive issues. They developed conceptualisations of the business reality and discussed the performance consequences of various distribution formats, but showed limited interest in providing managerial recommendations.

The first major re-orientation of the view of distribution was launched by Alderson (1957), later followed by Alderson (1965). These books emphasised the need for a holistic perspective on distribution. Alderson's approach to integrating the functional, institutional and commodity aspects were inspired by developments in organisation theory. Alderson claimed that the primary task of distribution was the connecting of "the technology of production" with "the technology of use". The conceptualisation of this phenomenon was identified as an "organised behaviour system", configured as a set of actions of which individual firms are elements. Alderson argued that such systems require coordination because the activities of one firm supplement the activities of other firms. Despite this claim for coordination, also Alderson was quite unclear regarding managerial recommendations. His main contribution was the advanced conceptualisation of the contemporary business reality. Although Alderson's books and papers were well received, they never got the attention they deserved, neither in research nor in practice (Shaw and Jones, 2005). According to Gattorna (1978, p. 488) "few channel theorists at the time really understood what Alderson was saying", and therefore his "ideas were unfortunately before their time". It goes without saying that it was even more difficult for practitioners to grasp the managerial implications of his thinking, although improvement of practice was always an underlying objective for Alderson (Hostiuck and Kurtz, 1973).

\section{The channel management perspective}

One of the reasons for the reluctance in relation to the Aldersonian framing was the simultaneous evolvement of an alternative school-of-thought. This approach had a clear managerial orientation and was easier to understand and apply. The evolving perspective is known as "marketing management", originating in Howard (1957) and his "marketing decision variables" and further refined through the notion of a "marketing mix" (Kotler, 1967). Marketing management was based on a producer orientated approach to business exchange, which replaced the more systemic views applied previously. Moreover, in the early texts on distribution, marketing was identified as a sub-function within the broader area of distribution. In marketing management models, distribution issues became reduced to one of the four Ps within the marketing mix of a selling firm.

The channel management approach was influenced also by concepts stemming from the "behavioural and social" schoolof-thought, launched primarily in Stern (1969). Channel management tended to adopt the "confrontational" concepts from this school, implying that "a focus on power-dependence and conflict dominated", both channel literature and channel research (Wilkinson, 2001, p. 34). These features contrasted 
Alderson's view that emphasised the importance of collaboration in the organised behaviour systems as a significant complement to mainstream attention to competitive and confrontative aspects.

The channel management view transferred distribution "from a system-wide perspective to a focus on how the channel captain should behave to secure an efficient distribution of his product" (Gripsrud, 2004, p. 195). Furthermore, Bartels (1988) commented that the broad subject area of distribution had become separated into "two halves". Mainstream marketing was dealing with the social and communicative aspects of the exchange, while the physical distribution aspects were treated in the evolving field of logistics. For these reasons, Alderson's holistic framing of the connection between the technology of production and the technology of use was disintegrated and replaced by frameworks focussing on one of the two halves in isolation - sometimes even specialising on limited aspects of these halves (Gadde, 2016).

The fundamental principles and instruments of channel management were fully developed at the beginning of the 1970s. The producer-centred perspective implied that the business processes were seen "through the eyes of marketing management in producing and manufacturing firms" (Rosenbloom, 1987, p. 4). The main distribution task concerned the "channelling out" of products from the manufacturing facilities. The leadership role of the channel captain in such operations was secured "through the effective use of power to achieve control" (Rosenbloom, 1987, p. 223). These features, in combination with general recommendations at the time to avoid dependence on individual business partners, resulted in arm's-length relationships between channel members. In these constellations "loosely aligned and relatively autonomous manufacturers, wholesalers and retailers [...] customarily bargained aggressively with each other" (Davidson, 1970, p. 7). When these conditions are at hand, the business exchange is most often standardised because adaptations are avoided, as they would impose unwanted dependencies. Such settings tend to rely on the principle of speculation (Bucklin, 1965), featuring mass production and mass distribution, in turn, requiring huge inventories at several levels in the channel to compensate for long lead times in production and distribution. However, in the late 1900s, the evolution of the business context made channel management less relevant and paid the way for current arrangements, featuring network-like constellations.

\section{The evolution of the transformation}

\section{The changing features of the business reality}

The channel management approach departed from the technology of production and focussed on the distribution of goods to those involved in the technology of use. This orientation relied on standardisation - "standardisation of taste that allowed for standardised design, standardisation of design that allowed for mechanised mass production and a standardisation of products that allowed for mass distribution" (Lampel and Mintzberg, 1996, p. 21). Standardisation was favourable to cost efficiency, which was beneficial also to buyers but gave little room for adaptations to individual requirements. Over time, however, technological developments in production and logistics reduced the advantages of large-scale operations and enabled customisation at reasonable costs (Hayes and Pisano, 1994; Christopher and Towill, 2001). These conditions facilitated a shift of focus from the output operations of manufacturers and put the emphasis on the requirements from individual end-users, increasingly demanding flexibility rather than standardisation (Gunasekaran and Ngai, 2005; Kozlenkova et al., 2015).

Technology advancement, especially related to the exchange of information, was significant for the customised solutions, as technical improvements enabled increasing reliance on "maketo-order" production. A study of innovative distribution configurations in the US concluded that these arrangements were made possible through "information technology and integrated logistics systems that can monitor the availability of products and services, process orders and deliver products and services rapidly" (Narus and Anderson, 1996, p. 114). The significant impact of information technology on distribution constellations has been further strengthened over time regarding supply chain synchronisation (Garcia-Dastugue and Lambert, 2003), enhanced attention to electronic commerce (Watson et al., 2015) and the role of social media (Krafft et al., 2015). Altogether, this shift of the starting point from the technology of production to the technology of use, totally twisted some of the previous basic principles for efficient and effective organising of distribution: "from scale to scope, from speculation to postponement, from push to pull" (Maruyama, 2004, p. 36).

The shift from speculation to postponement made it possible to reduce the substantial inventories featuring the channel management epoch (White and Pearson, 2001). The implementation of just-in-time deliveries and systems for efficient consumer response were important determinants of these changes (Gadde, 2016). Furthermore, make-to-order was increasingly applied as a complement to sales-from-shelves for many products, involving, for example, PCs and cars (Gunasekaran and Ngai, 2005). Supply systems relying on these principles tend to feature greater interdependencies than previous configurations, where inventories served as buffers between the operations. Other factors raising the complexity of the evolving distribution arrangements concerned increasing globalisation (Kozlenkova et al., 2015; Watson et al., 2015), greater environmental uncertainty (Kozlenkova et al., 2015) and more complex and dynamic marketplaces (Krafft et al., 2015).

The diverse demands from end-users required a mixture of constellations to satisfy individual customers, resulting in the development of multi-channels (Wilson and Daniel, 2007; Neslin and Shankar, 2009), later followed by reliance on omnichannels (Verhoef et al., 2015; Yrjölä et al., 2018). These network-like configurations include not only "traditional" intermediaries but also new types of actors specialising in logistics services (Selviaridis and Spring, 2007) and information exchange (Gadde, 2004). The effective functioning of these network arrangements required that previous hostile and arm's-length conditions were abandoned.

Increasing customisation and adaptations in relation to business partners made it necessary for firms to engage in longterm relationships, also involving joint investments (Lampel and Mintzberg, 1996). In many cases, such features tended to 
replace previous antagonistic relationships favouring independence (Wilkinson, 2001). Firms now deliberately entered situations of interdependence, as potential relational benefits cannot be obtained without such conditions. Hoyt and Huq (2000) concluded that producer-distributor relationships had evolved from transactional processes based on arm'slength conditions to collaborative partnerships. In a similar vein, Buzzel and Ortmeyer (1996) found that formerly adversarial relations between wholesalers and retailers had changed to more cooperative relationships. Frazier and Antia (1995) reported that examples abound of how retailers, distributors and manufacturers were developing closer relationships to improve their joint performance. Daugherty et al. (2006, p. 61) exemplified these benefits in terms of "improved customer service, better inventory management, more efficient use of resources, reduced cycle-times and increased information sharing". More recently, Choi and Hara (2018) showed that adaptations in terms of "resource specificity" and "activity tailoredness" between wholesalers and manufacturers provided positive effects for channel performance.

\section{The need for new conceptualisations}

The developments of the business reality called for new concepts and models to complement the channel management vocabulary. The producer orientated focus was no longer the most appropriate framing. Firstly, as mentioned above, the shift from speculation to postponement made end-users increasingly influential in the configuration of the distribution arrangements. Secondly, there were a striking shift in power from manufacturers to intermediaries (Hingley et al., 2015), exemplified by large wholesalers, mega-retailers and logistics service providers (Olsson et al., 2013). Thirdly, in the evolving business reality, the interaction between firms was essential for performance improvements. Narus and Anderson (1987, p. 35) argued that such benefits require productive partnerships grounded in "coordinated actions directed at mutual objectives, strategies and tactics that are consistent across organisations". One decade later the same authors found in their study of distribution innovations in the US that these pioneering organisations "realise that by sharing their resources and capabilities in novel ways and new situations they can take advantage of profit-making opportunities they could not exploit on their own" (Narus and Anderson, 1996, p. 112).

Performance enhancements also arise because the productive partnerships discussed above are connected to other relationships in larger constellations. It is the combined efforts of the firms in these settings that promote efficiency and effectiveness. Empirically such networked arrangements were observed by, for example, Anderson et al. (1997) in the form of "networks of value-adding partnerships". In a similar vein, Narus and Anderson (1996) concluded that the evolving and innovative configurations in their study could be best described as "webs of capabilities" embedded in an "extended enterprise".

Based on the evolving features of the business reality, arguments for a network framing of distribution were presented by researchers from diverse schools-of-thought. Not surprisingly, representatives of the IMP community suggested such frameworks (Wilkinson, 2001; Gadde and Ford, 2008).
Furthermore, one well-known advocate of the transaction cost approach claimed that individual relationships tend to be embedded in a context of other relationships, that may have implications for governance (Heide, 1994). From supply chain management it was concluded that a supply chain represents a web of multiple business networks and relationships (Min and Zhou, 2002). Finally, from an agency theory point of departure, it was argued that capturing the complexity of distribution required analysis of how dyads are embedded in larger constellations (Rokkan and Haugland, 2002).

More recent arguments for holistic framings have been presented by, for example, Kozlenkova et al. (2015), declaring the need for a more complete view of supply chain issues. Similar points are raised by Watson et al. (2015) to improve the understanding of how changes in one part of the "channel ecosystem" affect other parts. Moreover, it is claimed that the evolvement of omni-channels requires holistic framings for improved understanding and analysis (Eyuboglu et al., 2017; Yrjölä, 2018). Other proponents of a network perspective include Krafft et al. (2015) in the conclusion that networks matter greatly and Ellram and Ueltschy-Murfield (2019), arguing that business relationships in supply chains operate within the broader context of supply networks. Watson et al. (2015, p. 7), declare that "channels are interconnected networks of relationally bounded social entities, for whom longterm cooperation is critical to success", and therefore "network theory should provide an excellent framework". Finally, Tse et al. (2019, p. 310) conclude that rapidly changing and increasingly complex market environments "call for the explicit incorporation of a network view in any study of channel relationships".

\section{Modifications of managerial recommendations}

The changes in the business reality made the managerial issues in distribution more complex than before because of the extended interdependencies amongst distribution activities and the increasing relationship involvement (Gadde, 2004). In particular, the evolvement of omni-channels is significant in this respect, as these constellations are multifaceted and demanding when it comes to managerial action (Eyuboglu et al., 2017). Moreover, Verhoef et al. (2015) claim that the borders between the various arrangements in omni-channels become blurred. Therefore, today's complex distribution configurations require interfirm coordination of the interdependencies featuring activities, actors and resources (Kozlenkova et al., 2015). Swoboda et al. (2008, p. 66) argue that the need for coordination is especially great "when there is a substantial division of labour, great complexity and intensity of relationships between the elements" - aspects that are significant features of the current distribution reality. The crucial role of digitalisation in such coordination contexts is pointed out by Ruiz-Alba et al. (2020).

The claim for coordination is an outcome not only of the current changes in the business context. On the contrary, coordination has always been an important issue in distribution but needs to take new forms in today's business reality. Already 50 years ago, early advocates of the behavioural school explained the need to coordinate the activities of the organisations involved in distribution, as reported by Payan (2007). Coordination continued to be on the top of the 
management agenda during the channel management epoch. For example, Bucklin (1973) launched a theory of channel control for improving the coordination of activities, which was considered a prerequisite for channel performance. Similarly, Robicheux and El-Ansary (1976, p. 25) claimed that "effective and efficient channel performance is dependent upon the coordination of channel tasks". In their channel management approach, coordination was assumed to be attained through the ambitions of channel leaders to apply authoritative control in relation to the decisions of other organisations through the exploitation of coercive and non-coercive power bases.

In the evolution of the current distribution configurations, coordination of activities represents a "fundamental decision variable" (Weitz and Jap, 1995). However, the authors also reported a shift in managerial practice away from coordination through authoritative control by channel captains, towards contractual and relational procedures. Regarding control, Cannon et al. (2000) argue that contracts represent the main mechanisms for improved coordination in distribution arrangements. However, there is no general agreement concerning the impact of contracts in the governing of interfirm relationships. For example, Samaha et al. (2011) observed that using contracts to manage relationships may function as a "double-edged sword". On the one hand, contracts can suppress the negative effects of conflict and opportunism. On the other hand, contracts also showed to have a significant negative effect on cooperation by creating a more formalised relationship environment.

In a similar vein, Yang et al. (2017) conclude that some researchers argue that contracts can effectively curtail opportunism and increase performance by specifying each partner's role, while others contend that contracts are unproductive because they are costly to craft and enforce. Jap and Ganesan (2000) found that applying explicit contracts was an inefficient mechanism, as this approach had an "undermining effect on commitment". This outcome is a consequence of the fact that explicit contracts "signal distrust and are often complex, which reduces flexibility and may subsequently lower relationship performance" (Jap and Ganesan, 2000, p. 241). Obviously, network coordination requires other coordination mechanisms, discussed in the following sections portraying the main features of network coordination.

\section{Central attributes of network coordination}

Above, the features of network coordination have been discussed in relation to the channel management approach and the current business reality. In this section, we bring up the main characteristics of the conceptualisations of distribution networks and the associated mechanisms for coordination. Moreover, it is discussed what is needed to further refine and improve "network coordination" as a framework for the analysis of the distribution reality and the formulation of managerial recommendations.

\section{Network conceptualisation of the distribution reality}

The relevance of a network framing of what is ongoing in the distribution reality has been emphasised for several decades (Narus and Anderson, 1996; Nevin, 1995; Kumar, 2005;
Payan, 2007). This claim was repeated more recently by Kozlenkova et al. (2015), who concluded that most channel insights was still based on either firm-level or dyadic research. Watson et al. (2015) acknowledge the benefits of the theory developed at the dyadic level, regarding exchange characteristics and interaction in relationships, but conclude that such dyadic approaches are too limited. The authors request more network-based research, as previous studies have shown that such framing "enables researchers to investigate channel problems and phenomena in ways that were not viable with a dyadic approach" (p. 14). Conceptualisations founded in network theory would be significant means for examining the increasing interdependencies and complexities in the current distribution arrangements. In this way, a network perspective would be a useful tool for Eyuboglu et al. (2017), who identified a lack of conceptualisations of the complexity inherent in omnichannel arrangements.

This paper advocates the IMP approach (Håkansson and Snehota, 1995) as a relevant network framing of the current distribution reality, particularly for its holistic nature and the focus on dynamics and interaction in connected business relationships. Also, representatives of other schools-of-thought suggest IMP theory as an appropriate analytical framework. One example is Ellram and Ueltschy-Murfield (2019, p. 42), who reviewed the literature on supply chain management in business markets and concluded that "given the strong relational focus [...] and the importance of context [...] the IMP interactive approach is a good fit for framing research". The basic ARA-model (portraying the interplay between activities, resources and actors) offers suitable concepts for the analysis of complex interdependencies related to activity coordination and resource combining (Håkansson and Snehota, 1995). As shown in Freytag et al. (2017), IMP concepts are useful for analysis of the integration of activities, the interfaces amongst resources and the interaction between actors.

The importance of novel concepts for examining problems arising from interdependencies was pointed out by Crowston (1997). In that paper, three types of interdependencies are identified. Firstly, "task-task dependencies" occur because all activities that involve more than one actor require division of labour amongst the actors and procedures for managing the activity interdependencies. Secondly, "resource-resource dependencies" are at hand because changes in one resource element impact other resource elements. The third form concerns "task-resource dependencies". These conditions arise when two activities use the same limited resource. The IMP framing seems highly relevant for such analysis, as these interdependencies coincide with those in focus in the ARA framework. The significance of the IMP concepts appears even more obvious in Crowston's definition of why the handling of interdependencies is necessary. This occurs "in situations where actors to achieve common goals are performing interdependent activities that may also require or create resources of various types" (Crowston, 1997, p. 159, italics in the original source).

Within IMP theory, substantial knowledge of the processes in the business reality is at hand regarding the relationship level and the network level. What is less well covered in the prevailing conceptualisations is the linkage between the two 
levels (Håkansson and Gadde, 2019). Therefore, a first step in the direction towards more articulated network framings of distribution would be to enhance the understanding of this connection. Håkansson and Gadde (2019) explore some of the features of this linkage through triadic analysis. Their examination differs from the conventional triadic analysis where the two parties in a relationship are supplemented with a third actor. Instead, they suggest the triad to be identified from the network level; for example, one supplier and two users, supplier-intermediary-user, supplier-user-service provider. Such analyses will demonstrate the linkages between the relationship level and the network level. Enhanced knowledge of this connection is important because the two in a dyad can then enrich their relationship with influences from the surrounding network and test what is developed in the relationship in a larger setting (Håkansson and Gadde, 2019).

In a similar vein, other researchers have shown that when relationship dyads are considered in a triadic perspective, a richer and more realistic view of a buyer-supplier relationship will emerge (Wu et al., 2010). Vedel (2016) provides an example of these conditions in a study of the benefits appearing when an intermediary's two relationships with one producer and one user were supplemented with a direct producer-user connection. Specific benefits tend to occur regarding change and dynamics, as "a triadic analytical framework unveils the relational dynamics played out in the collective whole" (Choi and $\mathrm{Wu}, 2009$, p. 10). In the same way, Ellram and UeltschyMurfield (2019) welcome the increasing attention to triadic studies because such research will enable an improved understanding of single dyads and how these relationships are part of larger networks. We share these standpoints and conclude that further research on triadic connections would be beneficial for the further refining of network conceptualisations.

\section{Joint coordination in networks}

In the section dealing with managerial recommendations, it was concluded that the forms of coordination through authoritative control applied in channel management are no longer appropriate in the business reality featuring increasing cooperation. Hopkinson and Blois (2014) declared that the new conditions would require a shift away from the "confrontational" mechanisms rooted in power and conflict. As shown above, several doubts were raised also regarding the relevance of coordination based on contracts. Rather, the evolving business context calls for joint coordinative efforts of actors in interaction that may provide shared visions, as well as common norms and relationship cultures. Dekker et al. (2019, p. 152) show that inter-organisational mechanisms are especially useful for performance improvements, "as the scope of the collaboration increases in terms of diversity and intensity of activities jointly conducted".

When these conditions are at hand, one could expect that "collaborative" constructs like trust and commitment should be most significant for the understanding of the relationship between coordination and performance. However, several studies conclude that these concepts are not as useful as assumed. For example, Hibbard et al. (2001) argued that most research on trust and commitment concentrates on the interrelationship between the two and their antecedents, rather than explore their consequences regarding coordination. In a substantial literature review, Young (2006) found that trust is linked to relationship performance but reveals very little about why it is so. Moreover, Chicksand (2015, p. 130) commented that partnerships tend to be driven by power differentials between the parties rather than by "less tangible attributes such as trust or commitment”. Finally, based on a literature review, Gadde (2016) concluded that cooperative concepts like trust and commitment showed to be less relevant than expected for the understanding of what constitutes effective coordination in the evolving distribution arrangements.

In the search for alternative coordinative mechanisms, Hingley (2005) claimed that the significance of power in close collaboration had been overlooked. Mainstream literature tended to emphasise positive relational factors like trust and commitment and neglect the fact that in the business reality, power was not only constantly present but also acceptable and workable. Hopkinson and Blois (2014) explained these conditions by claiming that research in distribution had stayed with the power-base theory developed in the 1950s. Within its original domain (social psychology), these framings had been refined and further developed, while channel researchers had not incorporated these modifications. The authors suggested an alternative interpretation of power, concerned with how power evolves from the shaping of consensus between business parties, implying that power is generative and need not be repressive. It might seem a paradox that power can provide a better understanding of coordinative issues in current distribution settings than more collaborative concepts. However, as shown below, similar arguments have been presented by several authors.

Frazier (1999) concluded that power is a misunderstood concept. Due to the focus on the impact of coercive power bases, researchers had found that relationships were negatively affected by power. Similar thoughts were expressed by Nevin (1995), who argued that power and dependence in fact represent the foundations of successful relationship exchange, even claiming that these conditions are the underlying roots of solidarity and trust. Moreover, Frazier and Antia (1995) observed that interdependence between two parties can lead to "joint power", which is likely to promote relational coordination because of the common interests of the parties. In a similar vein, Chicksand (2015) claimed that partnering is more likely to succeed when there are interdependencies between collaborating parties. Moreover, Gadde and Håkansson (2001) concluded that power in close relationships can be used constructively as a mechanism for establishing shared norms and expectations. Similarly, Benton and Maloni (2005) argued that appropriate use of power can strengthen relationships and enhance supply chain performance. Obviously, a firm's possession of power must be kept separate from the way power can be applied to support joint coordination. This is illustrated in a study by Siemieniako and Mitrega (2018, p. 99), where they recommend managers to be aware of the paradox that they "can improve their power position by getting closer to dominating customers and making relation-specific investments". Furthermore, they argue that managers must learn and leverage their own expertise in the relationships with their business partners. 
Moreover, Kumar (2005) criticised the mainstream view of power for being unidimensional and representing a zero-sum contest. Instead, he claimed, one becomes powerful by creating a network of mutual dependencies that tend to stimulate joint coordination. For analysis of these conditions, it is worthwhile to return to Emerson (1962), who is probably the most cited reference when it comes to the relationship between dependence and power. In the paper, he also discussed some other interesting issues that have not been on the top of the agenda. Firstly, he declared that power is not an attribute of an actor - it is always a property of a relation. Improved understanding of power, therefore, requires studies of interaction processes. Secondly, he concluded that in the long run, studies of "power networks" will become more important for a "more adequate understanding of more complex power structures" (Emerson, 1962, p. 41). Similar arguments are raised by Hingley et al. (2015). They conclude that most investigations of power are focussed on exchange in dual relationships, while there is a lack of multi-tier and network research. One exception is a study of "networked power", illustrating how power is constructed on the network level (Olsen et al., 2014). Their research enhances the knowledge of how power can be applied for network coordination in terms of influencing, leveraging and strategic manoeuvring.

Olsen et al. (2014) show also how network coordination evolves through the dynamics of power - how power is generated and emerges over time in networks. In this way, they support the criticism by Palmatier et al. (2013) that behavioural concepts such as power and trust in most situations are used as static measures. Instead of evaluating power at a specific point in time, the authors advocate the advantages of analysing dynamic aspects of the concept. They define these features as the "velocity" of the concept, which indicates the rate and direction of the impact. The authors show convincingly that applying these velocities would improve the understanding of the evolution of network coordination.

\section{Concluding discussion}

The main contribution of this paper is the analysis of the dynamics of the perspective on a business phenomenon. The paper shows how channel management over time was replaced by network coordination as the perspective on distribution that is considered most relevant. This transformation is explained through the interplay between the changing features of the business reality, the conceptualisations of this reality and the managerial recommendations derived from these conceptualisations. In particular, the study illustrates how new concepts and models were applied for the analysis of changing conditions in the business reality in terms of, for example, enhanced attention to the user side rather than the producer side and increasingly collaborative relationships. In the modifications of the business reality, technology appeared as a significant driving force. IT-development was crucial not only for improving the exchange of information between collaborating parties. IT was instrumental also in the restructuring of the distribution arrangements towards maketo-order production and reduced warehousing. Below, we bring up some other central findings from the study for further discussion.

\section{The dynamics of the perspective on a phenomenon}

The shifting perspectives on distribution provide an interesting illustration of the dynamics in the view of phenomena in research and practice. In the first reorientation of distribution frameworks, Alderson (1957) integrated the separate and specialised agendas developed within the functional, institutional and commodity schools into a holistic framework. However, as shown in this paper, the evolving schools related to marketing management and the behavioural/social approach, needed conceptualisations useful for their specific issues of interest. These disciplines required concepts and models adjusted to their situations, and therefore found Alderson's framing too comprehensive. This specialisation was favourable for the development within the two new disciplines but also caused fragmentation of the broader area of distribution.

When these conditions are at hand, advocates of more integrated perspectives can be anticipated to emerge because mainstream frameworks are perceived to provide too narrow conceptualisations of reality. Such dynamics are illustrated by the framings developed within IMP (first launched in Håkansson, 1982) and the service-dominant logic approach (Grönroos, 1994; Vargo and Lusch, 2004). The evolvement of these perspectives has been found to be caused by "fundamental dissatisfaction with the traditional ways of visualising, examining or carrying out some aspects of business" (Ford, 2011, p. 231). The launch of a new perspective is, thus, rooted in imperfections and drawbacks of the prevailing mainstream approach. These problems arise from an increasing mismatch between the features of the business reality and the models of this reality.

\section{The impact on the conceptualisations of reality}

Central aspects of transformations of perspectives are that established conceptualisations will be affected. New constructs are needed to demonstrate the impact of new conditions - in this case, illustrated by the role of interaction and relationships embedded in networks. Some of the previous concepts are likely to become obsolete, exemplified by the channel captain role. Other concepts may require re-interpretation to be useful in the changing business reality, as shown in this study regarding power. In channel management, power was applied mainly as a coercive tool. In network coordination, power is used as a mechanism to coordinate the efforts of business partners to join forces.

Moreover, perspectives that once were abandoned may revitalise. For example, network conceptualisations of distribution were suggested a long time ago. Breyer (1934) claimed that any distribution arrangement constitutes a network. Furthermore, Alderson (1957) argued that all activities are aspects of interaction in organised behaviour systems, related in an "ecological network". However, these perceptions of distribution were neglected in the shadow of the dominant channel management approach. In the changing distribution landscape of the late 1900s, these thoughts were awakened by representatives of various schools of thought. One example is that Alderson's framing of distribution showed to be perfectly useful for analysis of central features of the current business reality such as make-to-order deliveries (Hulthén and Gadde, 2007). 


\section{The complexity of managerial issues}

Current distribution configurations feature increasingly complex managerial issues. Eyubogly et al. (2017) conclude that today's arrangements represent a burden for managers, as they are risky, costly, cognitively demanding and signify a challenge regarding control. As shown throughout this paper, these conditions require extended coordination amongst firms. In such settings, both parties in a dyad are eager to secure joint relationship performance. In these efforts, each firm may be tempted to influence and, in some way, control the operations of the counterpart. Brown and Crosno (2019) show that both process control and output control are related positively to performance and satisfaction. For these reasons, effective evaluation of the operations of the business partner has become increasingly critical (Goyal and Mishra, 2019). One problem with such ambitions is that the more successful the single actor is to control these attempts - the less dynamic the network will become, as the degrees of freedom for the business partner may become severely constrained (Håkansson et al., 2009).

The joint coordination applied in networks builds on common visions to support collaboration. The parties in such relationships share some ideas for the future, but they also have individual visions that may contradict those of their business partners (Chicksand, 2015). In some situations, such discrepancies will impose conflict in the relationship and require managerial attention. Historically, conflict was perceived as dysfunctional, and therefore should be avoided. However, in today's arrangements also the conflict concept needs re-interpretation. Gadde and Håkansson (2001) claim that conflict may contribute to an atmosphere of creativity, thus promoting innovation and development. Furthermore, Claro et al. (2018) show that functional conflict (disagreements regarding ideas and opinions) is constructive and promotes performance in close relationships. In such constellations conflict cannot be escaped - the parties will always perceive some of the evolving conditions differently. Therefore, the business partners must handle conflicting issues before tensions escalate to become dysfunctional.

\section{Limitations and further research}

This study represents a modest attempt to illustrate the main aspects of the transformation of the perspective on distribution arrangements. The central feature of the new perspective is identified as network coordination. As shown in the paper, the relevance of network coordination is declared by many authors. Despite this fact, however, there is no unified perception of this perspective. The proponents of the need for a new view of distribution represent various schools-of-thought. Therefore, they are likely to regard the changing phenomenon from their specific angles with subsequent consequences for both conceptualisations and managerial recommendations.

Moreover, transformations will never be complete. Various parts of the business reality will be impacted differently by the context dynamics - some to a large extent and some to a limited. This means that previous conceptualisations may be highly relevant in parts of the business reality also after what is here identified as a perspective shift. Similarly, managerial recommendations based on the previous perspective are likely to continue to be applied alongside those derived from the novel one.
Finally, regarding future studies of the changing perspective on distribution, we concluded that improved network conceptualisations require more research on the linkage between the relationship level and the network level. In this respect, we argued that triadic analysis should be an appropriate first step for a better understanding of this connection. Moreover, we sided with authors claiming that the dynamic aspects - the velocity - of behavioural concepts need to be taken into consideration. Such analyses of the rate and direction of change of, for example, power and trust, are supposed to be more valuable analytic tools than the static features of the concepts that are normally applied.

\section{References}

Alderson, W. (1957), Marketing Behaviour and Executive Action, Richard D. Irwin, Homewood.

Alderson, W. (1965), Dynamic Marketing Behaviour, Richard D. Irwin, Homewood.

Anderson, E., Day, G. and Rangan, K. (1997), "Strategic channel design", Sloan Management Review, Vol. 38 No. 4, pp. 59-69.

Bartels, R. (1988), The History of Marketing Thought, Publishing Horizon, Columbus.

Benton, W. and Maloni, M. (2005), "The influence of power driven buyer/seller relationships on supply chain satisfaction", Fournal of Operations Management, Vol. 23 No. 1, pp. 1-22.

Breyer, R. (1934), The Marketing Institution, McGraw-Hill, New York, NY.

Brown, J. and Crosno, J. (2019), "Process and output control in marketing channels: toward understanding their heterogeneous effects", Fournal of Business \& Industrial Marketing, Vol. 34 No. 4, pp. 735-753.

Bucklin, L. (1965), "Postponement, speculation and the structure of distribution channels", fournal of Marketing Research, Vol. 2 No. 1, pp. 26-31.

Bucklin, L. (1973), "A theory of channel control”, fournal of Marketing, Vol. 37 No. 1, pp. 29-47.

Buzzel, R. and Ortmeyer, G. (1996), "Channel partnerships streamline distribution", Sloan Management Review, Vol. 36 No. 3, pp. 85-96.

Cannon, J., Achrol, R. and Gundlach, G. (2000), "Contracts, norms, and plural form governance", fournal of the Academy of Marketing Science, Vol. 28 No. 2, pp. 180-194.

Cherington, P. (1920), The Elements of Marketing, McMillan, New York, NY.

Chicksand, D. (2015), "Partnerships: the role that power plays in shaping collaborative buyer-supplier exchanges", Industrial Marketing Management, Vol. 48, pp. 121-139.

Choi, T. and Wu, Z. (2009), "Triads in supply networks: theorizing buyer-supplier-supplier relationships", fournal of Supply Chain Management, Vol. 45 No. 1, pp. 8-25.

Choi, Y. and Hara, Y. (2018), "The performance effect of inter-firm adaptation in channel relationships: the roles of relation-specific resources and tailored activities", Industrial Marketing Management, Vol. 70, pp. 46-57.

Christopher, M. and Towill, D. (2001), "An integrated model for the design of agile supply chains", International fournal of 
Physical Distribution E Logistics Management, Vol. 31 No. 4, pp. 235-246.

Claro, D., Vojnovskis, D. and Ramos, C. (2018), "When channel conflict positively affect performance: evidence from ICT supplier-reseller relationships", fournal of Business $\mathcal{E}$ Industrial Marketing, Vol. 33 No. 2, pp. 228-239.

Copeland, M. (1924), Principles of Merchandising, A. W. Shaw, Chicago.

Crowston, K. (1997), "A coordination theory approach to organizational process design", Organization Science, Vol. 8 No. 2, pp. 157-175.

Daugherty, P., Richey, G., Roath, A., Min, S., Chen, H., Arndt, A. and Genchev, S. (2006), "Is collaboration paying off for firms", Business Horizons, Vol. 49 No. 1, pp. 61-70.

Davidson, W. (1970), "Changes in distribution institutions", Fournal of Marketing, Vol. 34 No. 1, pp. 1-10.

Dekker, H., Donada, C., Mothe, C. and Nogatchewsky, G. (2019), "Boundary spanner relational behavior and interorganizational control in supply chain relationships", Industrial Marketing Management, Vol. 77, pp. 143-154.

Ellram, L. and Ueltschy-Murfield, M. (2019), "Supply chain management in industrial marketing - relationships matter", Industrial Marketing Management, Vol. 79, pp. 36-45.

Emerson, R. (1962), "Power-dependence relations", American Sociological Review, Vol. 27 No. 1, pp. 31-41.

Eyuboglu, N., Kabaday, S. and Buja, A. (2017), "Multiple channel complexity: conceptualization and measurement", Industrial Marketing Management, Vol. 65, pp. 194-205.

Ford, D. (2011), "IMP and service-dominant logic: divergence, convergence and development", Industrial Marketing Management, Vol. 40 No. 2, pp. 231-239.

Frazier, G. (1999), "Organizing and managing channels of distribution", Fournal of the Academy of Marketing Science, Vol. 27 No. 2, pp. 226-240.

Frazier, G. and Antia, K. (1995), "Exchange relationships and interfirm power in channels of distribution", fournal of the Academy of Marketing Science, Vol. 23 No. 4, pp. 321-326.

Freytag, P.V., Gadde, L.E. and Harrison, D. (2017), "Interdependencies: blessings and curses", in Håkansson, H. and Snehota, I. (Eds), No Business is an Island: Making Sense of the Interactive Business World, Emerald Publishing, Bingley, pp. 235-252.

Gadde, L.E. (2004), "Activity coordination and resource combining - implications for relationship involvement and the relationship atmosphere", fournal of Marketing Management, Vol. 20 No. 1-2, pp. 157-184.

Gadde, L.E. (2014), "Distribution network dynamics and the consequences for intermediaries", Industrial Marketing Management, Vol. 43 No. 4, pp. 622-629.

Gadde, L.E. (2016), "The rise and fall of channel management", IMP fournal, Vol. 10 No. 1, pp. 129-153.

Gadde, L.E. and Ford, D. (2008), "Distribution research and the industrial network approach", IMP fournal, Vol. 2 No. 3, pp. 36-52.

Gadde, L.E. and Håkansson, H. (2001), Supply Network Strategies, Wiley, Chichester.

Gadde, L.E. and Hulthén, K. (2016), "Wroe Alderson, IMP, and the evolution of theory", IMP fournal, Vol. 10 No. 3, pp. 390-408.
Garcia-Dastugue, S. and Lambert, D. (2003), "Internetenabled coordination in the supply chain", Industrial Marketing Management, Vol. 32 No. 3, pp. 251-263.

Gattorna, J. (1978), "Channels of distribution conceptualizations: a state-of-the-art review", European fournal of Marketing, Vol. 12 No. 7, pp. 469-512.

Goyal, V. and Mishra, P. (2019), "Evaluating channel partner's performance: impact of task environments on the relevance of measurement metrics", Fournal of Business $\mathcal{E}$ Industrial Marketing, Vol. 34 No. 2, pp. 488-504.

Gripsrud, G. (2004), "The marketing discipline and distribution research: Time to regain lost territory", in Håkansson, H., Harrison, D. and Waluszewski, A. (Eds) Rethinking Marketing. Developing a New Understanding of Markets, Wiley, Chichester.

Grönroos, C. (1994), "From marketing-mix to relationship marketing - towards a paradigm shift in marketing", AsiaAustralian Marketing fournal, Vol. 2 No. 1, pp. 9-29.

Gunasekaran, A. and Ngai, E. (2005), "Build-to-order supply chain management: a literature review and framework for development", Fournal of Operations Management, Vol. 23 No. 5, pp. 423-451.

Håkansson, H. (Ed.) (1982), International Marketing and Purchasing of Industrial Goods. An Interaction Approach, Wiley, Chichester.

Håkansson, H. and Gadde, L.E. (2019), "Network triads - the linkages between small and large worlds", Proceedings of the 35th IMP Conference, ISEG, Paris, 28-30 August.

Håkansson, H. and Snehota, I. (1995), Developing Relationships in Business Networks, Routledge, London.

Håkansson, H., Ford, D., Gadde, L.E., Snehota, I. and Waluszewski, A. (2009), Business in Networks, Wiley, Chichester.

Hayes, R. and Pisano, G. (1994), "Beyond world class: the new manufacturing strategy", Harvard Business Review, Vol. 72 No. 1, pp. 77-86.

Heide, J. (1994), "Interorganizational governance in marketing channels", Fournal of Marketing, Vol. 58 No. 1, pp. 71-85.

Hibbard, J., Kumar, N. and Stern, L. (2001), "Examining the impact of destructive acts in marketing channel relationships", Fournal of Marketing Research, Vol. 38 No. 1, pp. 45-61.

Hingley, M. (2005), "Power to all our friends? Living with imbalance in supplier-retailer relationships", Industrial Marketing Management, Vol. 34 No. 8, pp. 848-858.

Hingley, M., Angell, R. and Lindgreen, A. (2015), "The current situation and further conceptualization of power in industrial markets", Industrial Marketing Management, Vol. 48, pp. 226-230.

Hopkinson, G. and Blois, K. (2014), "Power-base research in marketing channels: a narrative review", International fournal of Management Reviews, Vol. 16 No. 2, pp. 131-149.

Hostiuck, T. and Kurtz, D. (1973), “Alderson's functionalism and the development of marketing theory", Fournal of Business Review, Vol. 1 No. 2, pp. 141-156.

Howard, J. (1957), Marketing Management: Analysis and Decision, Richard, D. Irwin, Homewood.

Hoyt, J. and Huq, F. (2000), "From arm's length to collaborative relationships in the supply chain", International 
Fournal of Physical Distribution \& Logistics Management, Vol. 30 No. 9, pp. 750-764.

Hulthén, K. and Gadde, L.E. (2007), "Understanding the 'new' distribution reality through 'old' concepts: a renaissance for transvection and sorting", Marketing Theory, Vol. 7 No. 2, pp. 184-207.

Jap, S. and Ganesan, S. (2000), "Control mechanisms and the relationship life-cycle: implications for safeguarding specific investments and developing commitments", fournal of Marketing Research, Vol. 38 No. 2, pp. 227-245.

Kotler, P. (1967), Marketing Management, McGraw-Hill, Englewood Cliffs.

Kozlenkova, I., Hult, T., Lund, D., Mena, J. and Kekec, P. (2015), " The role of marketing channels in supply chain management”, fournal of Retailing, Vol. 91 No. 4, pp. 586-609.

Krafft, M., Goetz, O., Mantrala, M., Sotgiu, F. and Tillmanns, S. (2015), " The evolution of marketing channel research domains and methodologies: an integrative review and future directions", fournal of Retailing, Vol. 91 No. 4, pp. 569-585.

Kumar, N. (2005), "The power of power in supplier-retailer relationships", Industrial Marketing Management, Vol. 34 No. 8, pp. 863-866.

Lampel, J. and Mintzberg, H. (1996), " Customizing customization”, Sloan Management Review, Vol. 38 No. 1, pp. 21-30.

Maruyama, M. (2004), "Japanese distribution channels. Structure and strategy", fapanese Economy, Vol. 32 No. 3, pp. 27-48.

Min, H. and Zhou, G. (2002), "Supply chain modelling: past, present and future", Computers \& Industrial Engineering, Vol. 43 Nos No. 1-2, pp. 231-249.

Narus, J. and Anderson, J. (1987), "Distributor contributions to partnerships with manufacturers", Business Horizons, Vol. 30 No. 5, pp. 33-42.

Narus, J. and Anderson, J. (1996), "Rethinking distribution adaptive channels", Harvard Business Review, Vol. 74 No. 4, pp. 112-120.

Neslin, S. and Shankar, V. (2009), "Key issues in multichannel customer management: current knowledge and future directions", fournal of Interactive Marketing, Vol. 23 No. 1, pp. $70-81$.

Nevin, J. (1995), "Relationship marketing and distribution channels: exploring fundamental issues", fournal of the Academy of Marketing Science, Vol. 23 No. 4, pp. 327-334.

Olsen, P.I., Prenkert, F., Hoholm, T. and Harrison, D. (2014), "The dynamics of networked power in a concentrated business network", fournal of Business Research, Vol. 67 No. 12, pp. 2579-2589.

Olsson, R., Gadde, L.E. and Hulthén, K. (2013), "The changing role of middlemen - strategic responses to distribution dynamics", Industrial Marketing Management, Vol. 4 No. 7, pp. 1131-1140.

Palmatier, R., Houston, M., Dant, R. and Grewal, D. (2013), "Relationship velocity: toward a theory of relationship dynamics", fournal of Marketing, Vol. 77 No. 1, pp. 13-30.

Payan, J. (2007), “A review and delineation of cooperation and coordination in marketing channels", European Business Review, Vol. 19 No. 3, pp. 216-233.
Robicheux, R. and El-Ansary, A. (1976), “A general model for understanding channel member behavior", fournal of Retailing, Vol. 52 No. 4, pp. 13-30.

Rokkan, A. and Haugland, S. (2002), "Developing relational exchange - effectiveness and power", European fournal of Marketing, Vol. 36 Nos 1/2, pp. 211-230.

Rosenbloom, B. (1987), Marketing Channels. A Management View, The Dryden Press, New York, NY.

Ruiz-Alba, J., Gueselaga, R., Ayestarán, R. and Morales Mediana, J. (2020), "Interfunctional coordination: the role of digitalization", fournal of Business E Industrial Marketing, Vol. 35 No. 3, pp. 404-419.

Samaha, S., Palmatier, R. and Dant, R. (2011), "Poisoning relationships: perceived unfairness in channels of distribution", fournal of Marketing, Vol. 75 No. 3, pp. 99-117.

Selviaridis, K. and Spring, M. (2007), "Third party logistics: a literature review and research agenda", The International Fournal of Logistics Management, Vol. 18 No. 1, pp. 125-150.

Shaw, A. (1912), "Some problems in market distribution", The Quarterly Fournal of Economics, Vol. 26 No. 4, pp. 703-765.

Shaw, E. and Jones, B. (2005), "A history of schools of marketing thought", Marketing Theory, Vol. 5 No. 3, pp. 239-281.

Siemieniako, D. and Mitrega, M. (2018), “ Improving power position with regard to non-mediated power sources - the supplier's perspective", Industrial Marketing Management, Vol. 70, pp. 90-100.

Stern, L. (Ed.) (1969), Distribution Channels. Behavioral Dimensions, Houghton Miffin, Boston.

Stern, L. and El-Ansary, A. (1982), Marketing Channels, Prentice Hall, Englewood Cliffs.

Swoboda, B., Foscht, T. and Cliquet, G. (2008), "International value chain processes by retailers and wholesalers - a general approach", fournal of Retailing and Consumer Services, Vol. 15 No. 2, pp. 63-77.

Tse, S., Wang, D. and Zhang, T. (2019), "The effects of distributor relationship commitment and relationship opportunism: the moderating roles of exchange uncertainties and network factors", Industrial Marketing Management, Vol. 83, pp. 301-313.

Vargo, R. and Lusch, R. (2004), "Evolving to a new dominant logic for marketing", fournal of Marketing, Vol. 68 No. 1, pp. 1-17.

Vedel, M. (2016), "The triad value function - theorizing the value potential of connected relationships", fournal of Business E Industrial Marketing, Vol. 31 No. 7, pp. 849-860.

Verhoef, P., Kannan, P. and Inman, J. (2015), "From multichannel retailing to omni-channel retailing", fournal of Retailing, Vol. 91 No. 2, pp. 174-181.

Watson, G., Worm, S., Palmatier, R. and Ganesan, S. (2015), "The evolution of marketing channels: trends and research directions", fournal of Retailing, Vol. 91 No. 4, pp. 546-568.

Weitz, B. and Jap, S. (1995), "Relationship marketing and distribution channels", fournal of the Academy of Marketing Science, Vol. 23 No. 4, pp. 305-320.

Weld, L. (1916), The Marketing of Farm Products, McMillan, New York, NY.

White, R. and Pearson, J. (2001), "JIT, systems integration and customer service", International fournal of Physical 


\section{Lars-Erik Gadde}

Distribution \& Logistics Management, Vol. 3 No. 5, pp. 313-333.

Wilkie, W. and Moore, E. (2003), "Scholarly research in marketing: exploring the ' 4 eras' of thought development", Fournal of Public Policy \& Marketing, Vol. 22 No. 2, pp. 116-146.

Wilkinson, I. (2001), "A history of network and channels thinking in marketing in the $20^{\text {th }}$ century", Australasian Marketing Fournal (Amj), Vol. 9 No. 2, pp. 23-52.

Wilson, H. and Daniel, E. (2007), "The multi-channel challenge: a dynamic capability approach", Industrial Marketing Management, Vol. 36 No. 1, pp. 1-20.

Wu, Z., Choi, T. and Rungtusanatham, J. (2010), "Suppliersupplier relationships in buyer-supplier-supplier triads", fournal of Operations Management, Vol. 28 No. 2, pp. 115-123.
Volume $36 \cdot$ Number $13 \cdot 2021 \cdot 42-53$

Yang, P., Qian, L. and Zheng, S. (2017), "Improving performance and curtailing opportunism: the role of contractual issue inclusiveness and obligatoriness in channel relationships", Fournal of Business E Industrial Marketing, Vol. 32 No. 3, pp. 371-384.

Young, L. (2006), "Trust: looking forward and back", fournal of Business \& Industrial Marketing, Vol. 21 No. 7, pp. 439-445.

Yrjölä, M., Spence, M. and Saarijärvi, H. (2018), "Omnichannel retailing: propositions, examples and solutions", the international review of retail", Distribution and Consumer Research, Vol. 28 No. 3, pp. 259-276.

\section{Corresponding author}

Lars-Erik Gadde can be contacted at: lars-erik.gadde@ chalmers.se

For instructions on how to order reprints of this article, please visit our website:

www.emeraldgrouppublishing.com/licensing/reprints.htm

Or contact us for further details: permissions@emeraldinsight.com 